\title{
Rafael Valls Montés: Historia y memoria escolar. Segunda República, Guerra Civil y dictadura franquista en las aulas, Universitat de València, València, 2010, 170pp.
}

Enzo Traverso (Els usos del passat. Història, memòria, política: 2005 [2006]) ha estudiat els usos polítics de la memòria. És sabut que la interiorització crítica de fets passatsviscuts depèn, a banda de fets individuals, de la legitimació pública que se'n vulgui donar. Així existiria, segons aquest autor, una memòria dominant i una altra de subalterna. El primer model de memòria comptaria amb el suport dels pressupostos públics atès que comprendria la història que caldria recordar, socialitzar i que, en definitiva, serviria de cobertura jurídicolegal del règim polític a l'ús.

Aquesta recerca de Rafael Valls, sobre un cicle de temporal cultural i polític del tot significatiu, és un bon exemple per a tractar la vehiculació de l'imaginari pedagògic coetani i, alhora, tenir en compte, les continuïats, superacions i ruptures aconduïdes per les distintes estructures polítiques. Al capdavall, i és un aspecte derivat d'aquesta recerca (i d'una consideració metodològica general), el pensament i pràctiques pedagògiques són una conseqüència de la interdependència entre estructura social i estructura de poder.

En aquest sentit, l'anàlisi de la recepció de moviments socials i de conjuntures polítiques que han marcat un punt d'inflexió en l'evolució de les nacions és una recerca que es va establint amb rigorositat. Un estudi peoner fou el de la Fundació Jaume Bofill (A. Segura [coord.]: 2001), la investigació fou dedicada a estudiar el coneixement de la història pròpia i les temàtiques que tractaven amb més freqüència els manuals d'ensenyament secundari i de batxillerat.

Amb Historia y memoria escolar, I'historiador contemporani valencià Rafael Valls ha esbrinat -amb una acurada recerca d'àmbit peninsular pel que fa al buidatge dels manuals d'ensenyament mitjà i de l'ESO- quin és el vincle entre 'història' i subjecte en l'ensenyament mitjà (i superior).

L'objecte d'estudi de la recerca apuntada ha estat estudiar com hi han estat tractats la II República espanyola, la Guerra d'Espanya, el franquisme i la reforma política. L'abast temporal ha estat concebut de manera progressiva (1939-2003), és a dir, l'autor ha estudiat la socialització d'aquests fets d'ençà de la constitució de l'estat francofalangista fins a l'aplicació de la Llei Orgànica de Segon Ensenyament (LOGSE) a través de trenta-nou manuals de diverses editorials: confessionals i laiques. Finalment, 
l'assaig compta amb l'estudi d'una enquesta que Valls ha passat a alumnes i a professors de batxilerat i d'Universitat amb l'objecte de creuar les respostes i apreciacions sobre la metodologia, períodes més aprofundits i tractament dels períodes esmentats: èmfasi en qüestions sociopolítiques, culturals i econòmiques i recurs a formes explicatives a partir de dades iconogràfiques.

Així, el model de recerca de Valls -que pot ser complementat amb la realització d'estudis locals- palesa dos aspectes a destacar: la connotació política dels períodes citats i dels problemes vigents (model de ciutadania) que existeixen a l'hora de tractar determinats aspectes derivats del periode 1931-1939-1978.

Pel que fa a la connotació política. Del tractament dels textos, editorials i autors dels manuals de referència (vegeu el denominat 'gir' metodològic comprensiu més que no pas valoratiu de Vicens Vives i Santiago Sobrequés: 1954 [1957]) es constata una relació significativa entre el cicle polític dominant i la ideologia transmesa en les obres a I'hora de tractar, per exemple, I'antinòmia entre República i franquisme. És a dir, la deslegitimació republicana es defineix en proporció directa a les etapes del règim dictatorial i se'n matisen aspectes interns a partir de la "liberalització" de l'estat espanyol d'ença de 1959. Aquesta característica, en qualsevol cas, s'explicaria per les necessitats de la dictadura a cercar una obertura internacional d'ençà de 1953 (amb els EUA).

Aquest tipus de connotació, però, és pròpia de qualsevol historiografia i el tractament del cicle històric esmentat també és tractat amb peculiarietats ideològiques dins el procés de reforma política i de pacte institucional d'ençà de 1975. L'estat monàrquic, segons que es desprèn de les reflexions de Rafael Valls, modula fets i conjuntures, obviant aspectes conflictius (el caràcter de l'amnistia) i centralitzant, en canvi, el tractament de l'etapa republicana i de l'exili consegüent segons l'estratègia de l'oblit, que és determinant a l'hora de tractar la segona aportació que tot seguit destaquem d'aquest investigador, que ha destacat per els sevs recerques sobre les vinculacions internacionals de la dictadura primoriverista amb el feixisme italià.

Els problemes vigents derivats de l'enfocament de fets no situats estrictament en el republicanisme, sinó que són propis del franquisme i del procés reformista, plantegen noves metodologies $i$, en conseqüència, palesen el nivell d'implicació del sistema educatiu a fi de construir un hipotètic model de ciutadania.

Pel que fa a les noves metodologies explicatives i expositives, Valls destaca -en el context de renovació dels procediments "tècnics" i explicatius historiogràfics- que els manuals d'història contemporània apliquen progressivament didàctiques derivades dels recursos icònics (cartellisme, fotografies, il-lustracions) (pp. 114-117), de l'estudi de la cultura material coetània, de les històries de vida (familiars), de la microhistòria, de la història local. L'aportació bàsica d'aquests noves tècniques, que potser caldria no qualificar com a 'postmodernes' (p. 160), ha estat aprofundir en el coneixement del context històric $i$ en l'anàlisi de la vida quotidiana. Aquests extrems permeten d'articular, juntament amb les explicacions politològiques, ideològiques i culturals, 
una història sociològica (susceptible d'apuntar hipòtesis causals), i no tant descriptiva i centrada en superficials visions de conjunt.

Amb tot, els enfocaments disciplinars innovadors remeten a la capacitat de socialització. Aquesta qüestió es fonamental a l'hora de constatar la reproducció, o no, d'actituds i pràctiques cívicopolítiques dins la població dels estudiants. En aquest sentit, la hipòtesi per la qual es decanta Valls mostra en sintonia amb els objectius polítics determinats en el pla polític postfranquista: filtrar la memòria, construir la modalitat de l'oblit: "[el model hegemònic] consitiria en suministrar a los alumnos aquella versión o interpretación histórica que se considerase "adecuada" en cada momento, sea desde una valoración política sea desde su acreditación científica. En este enfoque se concede escasa importancia a los métodos y técnicas historiográficas y a la ejecución de los alumnos en los métodos de investigación. Se pretende privilegiar la generación de una identidad colectiva entre el alumnado y el fortalecimiento de la cohesión social" (p.16). Per la qual cosa no haria d'estranyar que manuals pertanyents a editorials alternatives com Akal no tinguin un suport majoritari en els centres educatius. I aquest aspecte és més destacat quan en teoria la conjutntura política estatal espanyola concordava amb un primer govern autodefinit com a socialista (pp. 28-29). La consideració de l'autor, doncs, és adient atès el percentatge significatiu d'alumnat (de secundària i àdhuc universitari) que desconeix (o ha après a oblidar) fets o cicles de la immediata contemporaneïtat. El que vol assenyalar Rafael Valls és que el model epistèmic que subjau a la majoria de manuals pedagògics comporta socialitzar un tipus determinat de futur ciutadà: aquell que reïx a l'addaptació a les circumstàncies. L'acriticisme, doncs, continua excel-lint en la relació ensenyamentaprenentatge, tot i el binomi 'coneixement i interès' aconduït en cada context viscut.

L'anàlisi de les dades de la rigorosa investigació apuntada duu a plantejar interrogants que han esdevingut reiteratius: quin grau de coneixement (i de reflexió) assumit existeix entre la població escolaritzada de la història nacional? I, en aquest sentit, quins són els condiconants externs que fan que el cicle republicà-repressiufranquista sigui hores d'ara si no el gran desconegut, sí el que compta amb un gradient de desmemòria més alt? En aquest sentit, el fil ideològicopolític de les politiques de la memòria tindria alguna cosa a dir-hi, perquè allò que al capdavall explicita la recerca de Rafael Valls, i com aquest autor introdueix en la part final de l'obra (pp.151-160), és com es gestiona (amb quins criteris: si metodològics o polítics) ${ }^{1}$ la identitat col-lectiva a través de la pròpia representació delpassat que no deixa de ser present.

L'escepticisme a què arriba l'autor de la investigació comentada (es guanya en formalització del text, però no en l'aprofundiment del coneixment crític dels fets socials) està plenament justificat. 


\section{Referències}

${ }^{1}$ Per aquest aspecte és essencial: J. Sisinio Pérez Garzón et alia: La gestión d ela memòria.La historia de España al servicio del poder, Crítica, Barcelona, 2000.

Xavier Ferré Trill, professor lector del Departament de Pedagogia de la Universitat Rovira i Virgili.

M. Isabel Miró Montoliu, professora titular del Departament de Pedagogia de la Universitat Rovira i Virgili. 